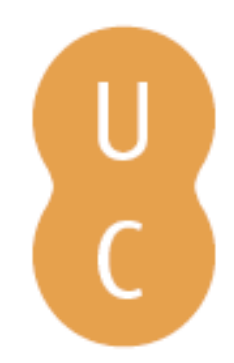

\title{
pompalina
}

\section{Acesso aos livros eletrônicos (e-books), disponíveis para a comunidade usp}
Autor(es): $\quad$ Nogueira, Adriana Hypólito; Marques, Eliana de Azevedo; Neves, Elisabete da Cruz

Publicado por: Imprensa da Universidade de Coimbra

URL

persistente:

URI:http://hdl.handle.net/10316.2/31959

DOI:

DOI:http://dx.doi.org/10.14195/978-989-26-0869-3_39

Accessed : $\quad$ 26-Apr-2023 13:42:54

A navegação consulta e descarregamento dos títulos inseridos nas Bibliotecas Digitais UC Digitalis, UC Pombalina e UC Impactum, pressupõem a aceitação plena e sem reservas dos Termos e Condições de Uso destas Bibliotecas Digitais, disponíveis em https://digitalis.uc.pt/pt-pt/termos.

Conforme exposto nos referidos Termos e Condições de Uso, o descarregamento de títulos de acesso restrito requer uma licença válida de autorização devendo o utilizador aceder ao(s) documento(s) a partir de um endereço de IP da instituição detentora da supramencionada licença.

Ao utilizador é apenas permitido o descarregamento para uso pessoal, pelo que o emprego do(s) título(s) descarregado(s) para outro fim, designadamente comercial, carece de autorização do respetivo autor ou editor da obra.

Na medida em que todas as obras da UC Digitalis se encontram protegidas pelo Código do Direito de Autor e Direitos Conexos e demais legislação aplicável, toda a cópia, parcial ou total, deste documento, nos casos em que é legalmente admitida, deverá conter ou fazer-se acompanhar por este aviso.

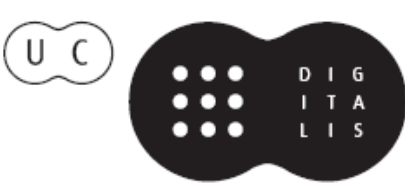


Maria Manuel Borges

Elias Sanz Casado

Coordenação

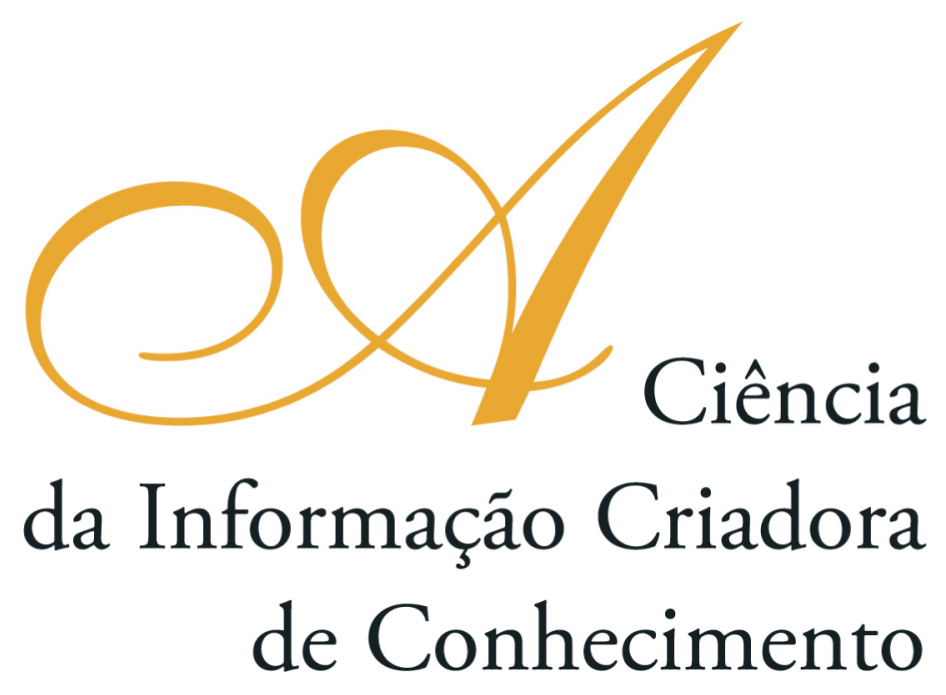

Vol. I I

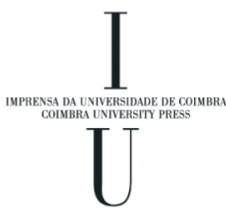

- COImbra 2009 


\title{
ACESSO AOS LIVROS ELETRÔNICOS (E-BOOKS), DISPONÍVEIS \\ PARA A COMUNIDADE USP
}

\author{
Adriana Hypólito Nogueira \\ Universidade de São Paulo (Brasil) \\ Eliana de Azevedo Marques \\ Universidade de Sáo Paulo (Brasil) \\ Elisabete da Cruz Neves \\ Universidade de São Paulo (Brasil)
}

\section{Introdução}

O Sistema Integrado de Bibliotecas da Universidade de São Paulo - SIBi/USP foi instituído pela Resolução n. 2226, de 08.07.1981, da Reitoria USP, com o objetivo de criar condiçóes para o funcionamento sistêmico das bibliotecas da USP afim de oferecer suporte ao desenvolvimento das atividades de ensino, de pesquisa e de extensão na Universidade.

O SIBi/USP é composto pelo conjunto de 43 bibliotecas, administrativamente ligadas às respectivas Unidades Universitárias, pelo Departamento Técnico do SIBi/ USP (DT/SIBi/USP), responsável pela coordenação técnica dos programas, projetos, diretrizes e procedimentos para o Sistema e pelo Conselho Supervisor do SIBi/USP, formado por docentes, indicados pelo Reitor da Universidade, por bibliotecários do Sistema, eleitos por seus pares, e pelo Diretor Técnico do SIBi/USP.

O CRUESP Bibliotecas iniciou suas atividades em 1999, como Grupo de Estudos, instituído pela Resolução do Conselho de Reitores das Universidades Estaduais Paulistas (CRUESP) 149/99, tendo por objetivo a integração dos Sistemas de Bibliotecas da USP, UNESP e UNICAMP.

O Consórcio CRUESP Bibliotecas, acompanhando essas facilidades e com a premissa da racionalização de recursos apresentou um projeto, com vistas à aquisição de livros eletrônicos, a Fundaçáo de Amparo à Pesquisa do Estado de São Paulo (FAPESP) dentro do Programa FAP - Livros, que prevê apoio à aquisição de livros necessários para a pesquisa científica e tecnológica.

A partir da aprovação desse projeto pela FAPESP, foi realizado um levantamento, junto às bibliotecas integrantes do Consórcio, para seleção de títulos de interesse de cada área.

Foram adquiridos mais de 250 mil títulos, de 11 bases de dados distintas, abrangendo todas as áreas do conhecimento, com acesso permanente a estes conteúdos, ou seja, temos a garantia de acesso ininterrupto, assim como acontece com a aquisição do acervo impresso, em que a biblioteca tem a posse do exemplar. 


\section{Objetivos}

Demonstrar o processo de implementação de uma Base de Busca Unificada, para acesso aos títulos de E-books, adquiridos pelo Consórcio CRUESP Bibliotecas e desenvolvida pelo Sistema Integrado de Bibliotecas da Universidade de São Paulo (SIBi/USP).

\section{Metodologia}

Para acessar os títulos era necessário entrar no site de cada base e realizar a pesquisa na plataforma do editor. Esse procedimento dificultava a busca para o usuário, pois era preciso repetir a estratégia de busca em cada base. Outro fator que não contribuía para um maior uso dos E-books era a diversidade entre as plataformas de pesquisa de cada editor.

O DT/SIBi/USP, em busca de otimizar o uso desses títulos e ampliar as facilidades de pesquisa para os seus usuários, decidiu desenvolver um sistema de busca unificada para esses títulos. Como, à época, a maioria das plataformas utilizadas pelos fornecedores não permitia o uso do Protocolo Z39.50 (protocolo cliente servidor de padrão internacional que permite pesquisa e recuperaçáo de informaçáo em redes de computadores distribuídos) foi necessário desenvolver a base unificada utilizando a linguagem Hypertext Preprocessor (PHP).

Para dar início às atividades, foi solicitado aos fornecedores o envio ao DT/SIBi dos registros bibliográficos de cada título adquirido. Recebemos arquivos tanto em formato Machine-Readable Cataloging (MARC 21) como em Excel. Todos os registros foram migrados para um banco de dados em MySQL, que é um sistema de gerenciamento de banco de dados (open-source), que utiliza Linguagem Structured Query Language - SQL (Linguagem de Consulta Estruturada) como interface. O MySQL interage perfeitamente com a linguagem PHP, selecionada para a construção da base de Busca Unificada. Após recebermos todos os registros bibliográficos, foi realizado um mapeamento de cada campo. Finalizada essa etapa definimos os campos para pesquisa: autor, título e ISBN. Iniciou-se, então, a fase de testes dessa base, envolvendo uma equipe de bibliotecários e analistas do DT/SIBi. Um tutorial de uso da Busca Unificada foi elaborado para apoio aos usuários.

\section{Resultados e Discussóes}

Apesar do aumento do uso dos livros eletrônicos pela comunidade USP, após treinamentos realizados, a resistência a este tipo de material ainda é expressiva, assim como, aconteceu durante a transiçáo do modo de acesso aos periódicos, de impresso para eletrônico. Entretanto, sabemos que essa resistência é temporária e as vantagens oferecidas pelo acesso eletrônico serão incorporadas no cotidiano de nossos pesquisadores. Cabe destacar, entre as facilidades: o acesso simultâneo por diversos usuários a um mesmo título, a antecipação da disponibilidade dos títulos em relação à publicação 
do material impresso, além da preservação física destes, a minimização de problemas relativos a espaços físicos, entre outras.

Outra vantagem que não podemos deixar de mencionar, é que o acesso aos livros eletrônicos, permite a leitura por softwares específicos para conversão de voz, atendendo a comunidade portadora de deficiência visual, agilizando a consulta e eliminando a etapa de digitalização do material.

Salientamos, que a implantaçâo desta base, não substituirá os acervos físicos das bibliotecas, mas sim agregará valor aos serviços tradicionais já oferecidos, incorporando a estes os recursos disponíveis atualmente pelas novas Tecnologias, na área da Ciência da Informação e Comunicação.

\section{Referências bibliográficas}

Anuradha, K. T., \& Usha, H. S. (2006). Use of E-books in an academic and research environment: a case study from the Indian Institute of Science. Program: Electronic Library and Information Systems, 40(1), 48-62.

Chartier, R. (1999). A aventura do livro: do leitor ao navegador. São Paulo: UNESP.

Marques, E. A. (2008/2009, dezembro/fevereiro). A nova biblioteca: o papel e o digital. Revista USP, São Paulo, 1, 18-27.

Nogueira, A. H., \& Salem, A. D. C. (2001). Banco de Dados Bibliográficos da USP - DEDALUS: uma proposta de atualizaçáo. Trabalho de Conclusão de Curso, Programa de Administração da Inovação Científica e Tecnológica nos Serviços de Informação / PROTAP - SIBi/USP, Faculdade de Economia, Administração e Contabilidade da Universidade de São Paulo, São Paulo.

Universidade de São Paulo. Sistema Integrado de Bibliotecas (2009). SIBiNet - Rede de Serviços do SIBi/USP. São Paulo: USP. Recuperado em 14 de abril de 2009 de http://www. usp.br/sibi 